\title{
Analysis on Spatial-Temporal Change of Construction Mechanics of Long-Span Disaster-Proof Half-Tunnel Structure System
}

\author{
Xiaojun $\mathrm{Ma}^{1}$, Shihua $\mathrm{Xia}^{2, *}$ \\ ${ }^{1}$ Qinghai Communications Construction Management Co, Ltd., Xining, Qinghai, 810003, China \\ ${ }^{2}$ China Merchants Chongqing Communications Technology Research \& Design Institute Co., Ltd., Chongqing, 400067, China
}

\begin{abstract}
Largely-rolling hills are widely distributed in China. In these areas, high-cut slope is common in road construction. Such form of construction usually causes excessive disturbance to hills and serious damage to vegetation, which is easy to induce natural disasters and affect traffic safety in the operation period. In order to protect the natural environment and prevent natural disasters, a new type of tunnel structure - long-span disaster-proof half-tunnel structure system - is increasingly used in highway tunnels. This type of structure involves a variety of constructions, necessitating a process of structural system conversion. For this reason, construction mechanics is unknown. In the context of the half-tunnel structure system of an expressway, this paper establishes 11 spatial-temporal conditions using the Load Release Coefficient of Slope, performs the coupled simulation of the half-tunnel combined system with the most unfavorable section through numerical calculation, analyzes the changes in the construction mechanics of the combined system under different working conditions, and proposes the good timing for construction of half-tunnel structure system according to the monitoring and measurement data obtained from the construction site. The result shows that the half-tunnel structure system is a system combining side slopes, backfilled masses and half-arch inclined-column structure, which interact with each other. The half-tunnel construction should allow for the coordination of the three combination factors. With an eye to assuring the safety and stability of structure system and making the structure solution economically feasible, it is supposed to be a good time to start the construction of half-tunnel structure system when about $70 \%$ of the stress inside slopes is released.
\end{abstract}

\section{Introduction}

China is a mountainous country. About $75 \%$ of the land is mountains or largely-rolling hills[1]. In road construction, the common practice in the past is to wind around a mountain or hill or cut its slope into a high-cut slope. The consequence is excessive disturbance to the mountain or hill, as a result of which landslides and other natural disasters easily happen in rainy days, thus affecting the traffic safety. As a new type of tunnel structure that can solve the above problem, long-span disaster-proof half-tunnel structure is increasingly used in highway tunnels[2]. The half-tunnel structure system is a system combining side slopes, backfilled masses and half-arch inclined-column structure. The analog computation of its construction mechanics must include the coupled computation of the structure combined system, which means the mountain or hill, backfill and half-arch inclined-column structure are modeled and analyzed as a whole. Considering the interaction among the three combination factors, the results of calculation using such model are closer to reality. In the context of the long-span disaster-proof half-tunnel structure system of an expressway, this paper gives the load release coefficient of slope, establishes different spatialtemporal conditions, creates the FEM model of the combined system for numerical simulation, and analyzes the spatial-temporal changes in the construction mechanics of the half-tunnel structure combined system according to the monitoring and measurement data obtained from the construction site.

\section{Project Overview}

\subsection{Project background}

The route optimization effects a high slope on the right side of the left line of the expressway. If the cutting solution is adopted for slope excavation, side slopes may be as high as about $72 \mathrm{~m}$. Due to this, there will be a lot of work to do with excavation and protection. In addition to leaving obvious trace of man-making and causing great damage to environment, this is not conducive to slope maintenance and operation safety after the project is put into operation. For the sake of disaster prevention

\footnotetext{
*Corresponding author: xiashihua@cmhk.com
} 
and mitigation, reduction of excavation and protection works, environmental protection and operation safety, it is designed to have a long-span disaster-proof halftunnel with a total length of $123 \mathrm{~m}$ on the left line of the high-slope section.

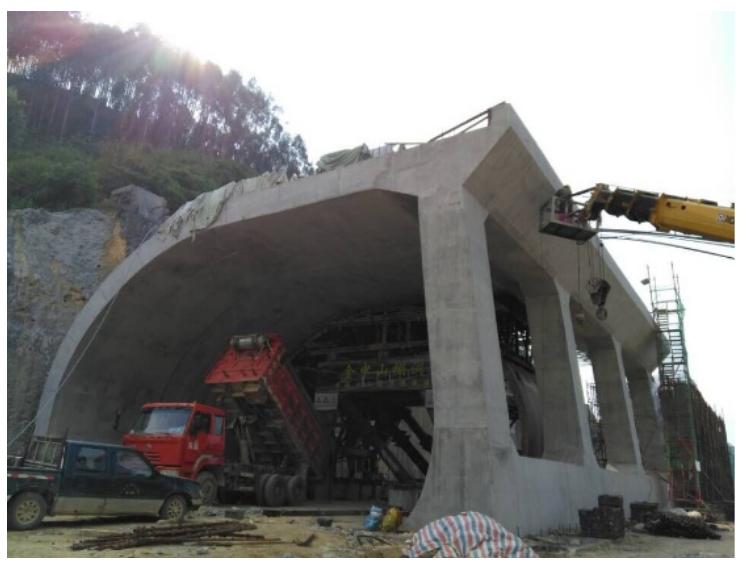

Fig. 1. Long-span Disaster-Proof Half-Tunnel Structure System of an Expressway.

\subsection{Engineering geological conditions}

The area where the half-tunnel is located is a largelyundulating low-hill area. The maximum ground elevation difference is more than $40 \mathrm{~m}$, the absolute elevation is between $70.76 \mathrm{~m}$ and $115.60 \mathrm{~m}$, and the natural slopes with a gradient of about $25-35^{\circ}$ are developed with vegetation. The surrounding rock is Gaotan Formation (V2g), Bacun Group, Cambrian System, which is composed of epimetamorphic sandstone. The surface layer is Quaternary deluvium, mainly composed of silty clay and gravelly soil. This layer of soil is about $2.2 \mathrm{~m}$ thick. It is underlain by strongly-weathered metamorphic sandstone of Gaotan Formation, Bacun Group, Cambrian System, which is Class III hard Soil to Class IV soft rock. Through multistage tectonic movement, the half-tunnel structure area has been transformed into an area with folds and faults, where the tectonic line mainly strikes NE-SW. This area has not been developed with surface water, and it is poor in groundwater and has no unfavorable and special geology.

\section{General Design and Construction Scheme of Half-Tunnel Structure System}

\subsection{General design}

With protection from pile anchorage or shotcrete rockbolt mesh, the near-hill side of the half-tunnel structure has a net clearance width and height of $15.5 \mathrm{~m}$ and $5.0 \mathrm{~m}$ respectively and an inner contour (inner section) area of $114.8 \mathrm{~m} 2$ (excluding invert). It is a oneway three-lane tunnel of half-arch inclined-column structure. A total of 16 inclined columns with a net height of $8.6 \mathrm{~m}$ are spaced $10 \mathrm{~m}$ apart from center to center. The bottom of inclined columns is integral castin-place reinforced concrete invert. The foundation of the half-tunnel structure on the near-hill side is consolidated by tremie grouting, and the inclined column side is consolidated with shallow-pile foundation. The general design is shown in Figure 2.

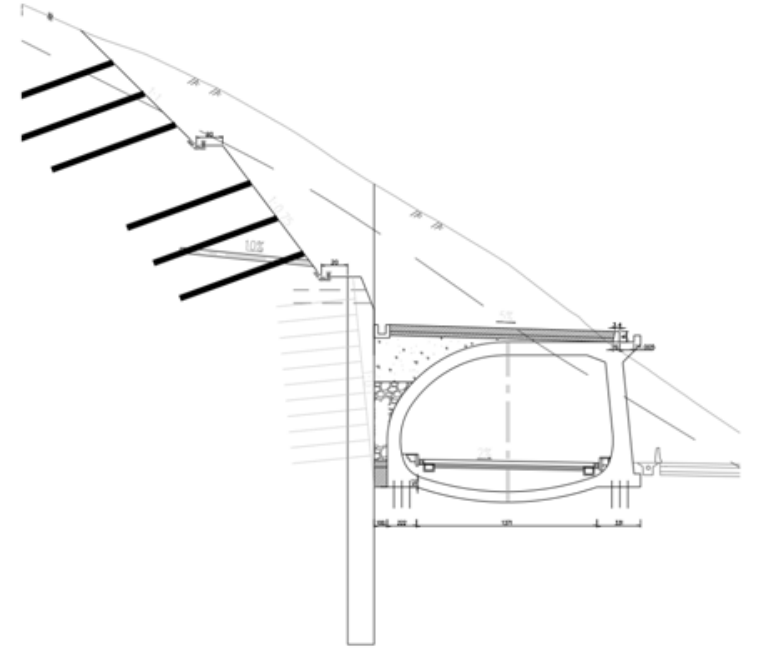

Fig. 2. General Design of Half-Tunnel Structure System.

\subsection{Construction scheme and basic procedure}

In addition to the reliability of structural design, the construction process is also the key to the success in the construction of half-tunnel structure system. The halftunnel structure is generally constructed by open-cut method. To be specific, this method is sloping first, then construction of half-arch inclined-column structure, and at last back-pressure backfilling and restoration of surface landscape. Side slopes are usually designed as temporary slopes, so the half-arch inclined-column structure is required to be concreted in time and provide an appropriate bearing capacity. The permanent stability of side slopes can be achieved by the back-pressure backfilling between the half-arch inclined-column structure and the side slope. Generally, a side slope is excavated section by section and block by block. This not only brings the spatial effect of the slope into play, but also shortens the exposure time of the slope. The construction of half-tunnel structure system is mainly divided into four key steps: slope excavation and protection, construction of half-arch inclined-column structure foundation and structure, construction of waterproofing and drainage system of half-tunnel structure, and backfilling and greening. Here is the actual construction sequence of half-tunnel structure system[3]:

Step 1: Surface clearance and construction of slope top intercepting ditch;

Step 2: Excavation and protection of third-stage side slope;

Step 3: Excavation and protection of second-stage side slope;

Step 4: Pre-consolidation and retaining structure construction of first-stage side slope; 
Step 5: Construction of pile-end anchor cable and excavation and protection of first-stage side slope;

Step 6: Construction of right-side dig-hole pile and invert of half-arch inclined-column structure;

Step 7: Concreting of inclined column;

Step 8: Concreting of joist; wall

Step 9: Concreting of slabbed construction of curved

Step 10: Construction of gravel blind ditch and tunnel-top drainage ditch and backfilling with gravelly soil.

\section{Analysis on Spatial-Temporal Change of Construction Mechanics}

\subsection{Load release coefficient of slope}

Just like the lining of mined tunnel, the choice of the construction time of the half-arch inclined-column structure in the half-tunnel structure system may also have a great impact on its own structural internal force and side slope stability. If the structure is constructed too early, most of the deformation pressure of the side slope may act on the structure through the backfilled mass, which could cause the structure to withstand too large internal force. If the structure is constructed too late, the temporarily-supported side slope may have too much deformation, and too large tensile stress may be produced on the top of the side slope, which could lead to the instability of the slope in the long-term operation, resulting in the instability of the whole half-tunnel structure system. In order to take into consideration the influence on the whole system from structure construction time and side slope deformation, the load release coefficient of slope $(\mathrm{K})$ is defined as the index of spatial-temporal change of construction mechanics of half-tunnel structure system. This index is similar to the load release coefficient of surrounding rock of mined tunnel in the New Austrian Tunnelling Method (NATM). After a period of slope deformation and stress redistribution following the slope excavation, the stress in the side slope is released to a certain extent. At this time, the half-arch inclined-column structure can be constructed to bear the residual deformation pressure of the side slope, making both the structure and slope stable. The percentage of released stress in the side slope is the load release coefficient of slope.

$$
K=\frac{\sigma_{t}}{\sigma} \times 100 \%
$$

Where: $\sigma_{t}$ is the stress released through the deformation of the side slope at a certain time node; $\sigma$ is the stress released through the complete deformation of the side slope.

\subsection{Calculation parameters}

According to the engineering geological investigation report and relevant specifications[4-6], the half-tunnel structure passes through the sections of moderately and strongly-weathered sandstone, which is overlain by artificial fill. The half-tunnel structure is C30 reinforced concrete structure. The values of calculated mechanical parameters of geotechnical and concrete materials are listed in Table 1 and Table 2.

Table 1. Physical and Mechanical Parameters of Geotechnical Materials.

\begin{tabular}{|c|c|}
\hline $\begin{array}{c}\text { Surrounding } \\
\text { Rock }\end{array}$ & $\begin{array}{c}\text { Strongly-weathered } \\
\text { metamorphic sandstone }\end{array}$ \\
\hline $\begin{array}{c}\text { Density, } \gamma \\
(\mathrm{kN} / \mathrm{m} 3)\end{array}$ & 20.5 \\
\hline $\begin{array}{c}\text { Basic Allowable } \\
\text { Value of } \\
\text { Foundation } \\
\text { Bearing Capacity } \\
(\mathrm{kPa})\end{array}$ & 350 \\
\hline $\begin{array}{c}\text { Poisson's Ratio } \\
(\mu)\end{array}$ & 0.40 \\
\hline $\begin{array}{c}\text { Cohesion C } \\
(\mathrm{kPa})\end{array}$ & 40.0 \\
\hline $\begin{array}{c}\text { Internal Friction } \\
\text { Angle, } \psi \\
\left({ }^{\circ}\right)\end{array}$ & 23.0 \\
\hline
\end{tabular}

Table 2. Physical and Mechanical Parameters of Concrete Materials.

\begin{tabular}{|c|c|}
\hline Material & C30 reinforced concrete \\
\hline $\begin{array}{c}\text { Density, } \gamma \\
(\mathrm{kN} / \mathrm{m} 3)\end{array}$ & 25 \\
\hline $\begin{array}{c}\text { Elasticity Modulus } \\
(\text { E/Mpa })\end{array}$ & 31000 \\
\hline $\begin{array}{c}\text { Poisson's Ratio } \\
(\mu)\end{array}$ & 0.2 \\
\hline $\begin{array}{c}\text { Tensile Strength } \\
(\text { Mpa })\end{array}$ & 2.2 \\
\hline $\begin{array}{c}\text { Compressive } \\
\text { Strength } \\
(\text { Mpa })\end{array}$ & 20 \\
\hline
\end{tabular}

\subsection{Calculation model}

In this FEM simulation, the most unfavorable section, that is, the highest section of slope excavation, is selected for calculation. The plane strain element is used to simulate the stratum, side slope and backfill, and the beam element is used to simulate the anchor cable, antislide pile, half-arch inclined-column and invert structure[7]. In addition, the side slope and structure are divided into more grids. The FEM model for coupled computation of half-tunnel structure system is shown in Figure 3. The changes in the internal force and stability of the structure and side slope at the construction time of the structure varying with the load release coefficient of slope $(\mathrm{K})$. In this computational simulation, the load release coefficient of slope under 11 working conditions 
is considered to be $0 \%, 10 \%, 20 \%, 30 \%, 40 \%, 50 \%$, $60 \%, 70 \%, 80 \%, 90 \%$ and $100 \%$ respectively.

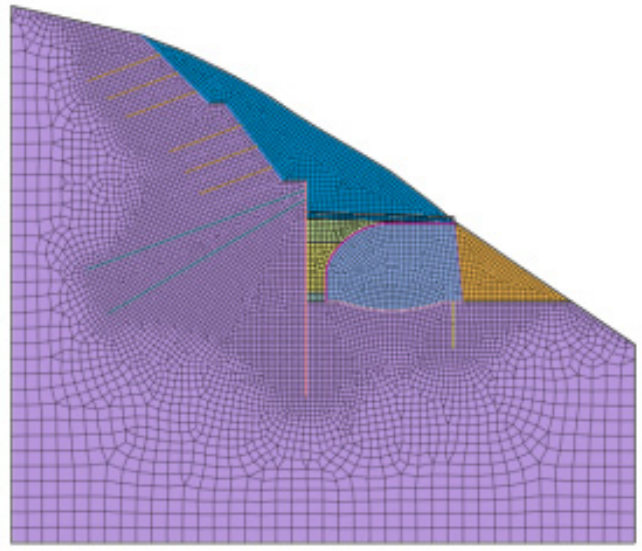

Fig. 3. FEM Model of Half-Tunnel Structure System.

\subsection{Simulation procedure}

The numerical simulation is a simplified simulation based on actual construction sequence. The process of computational simulation is divided into 5 stages and 8 steps:

Stage 1: simulation of initial geostress field;

Stage 2: (1) simulation of permanent side slope excavation, (2) simulation of prestressed anchor bolt support;

Stage 3: (1) simulation of anti-slide pile construction, (2) simulation of prestressed anchor cable support;

Stage 4: simulation of temporary side slope excavation;

Stage 5: (1) simulation of construction of half-arch inclined-column structure, (2) simulation of backfilling.

\subsection{Analysis on calculation results}

\subsubsection{Effect of different load release coefficients of slope on deformation of structure without side slope}

Despite different load release coefficients of slope, every component of the structure without side slope in the halftunnel structure system has displacement-induced deformation The results of deformation induced by horizontal and vertical displacement of anti-slide pile and half-arch inclined-column structure at the load release coefficient of slope of $0 \%$ to $100 \%$ are shown in Figure 4 and Figure 5.

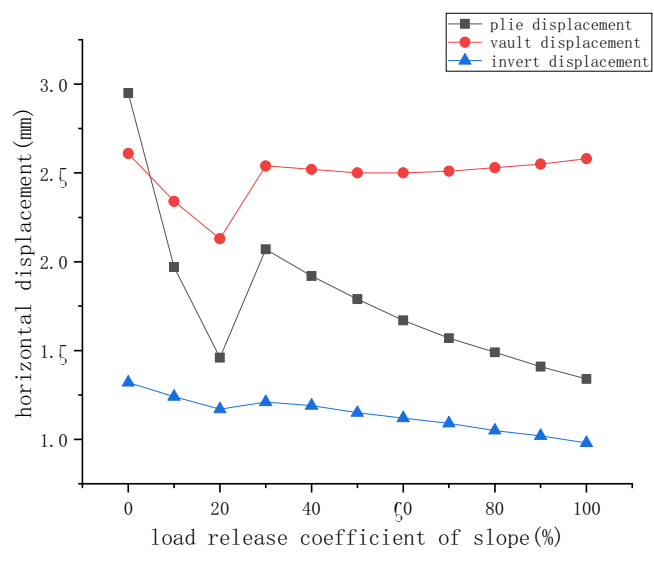

Fig. 4. Horizontal Displacement of Anti-Slide Pile and HalfArch Inclined-Column Structure (mm).

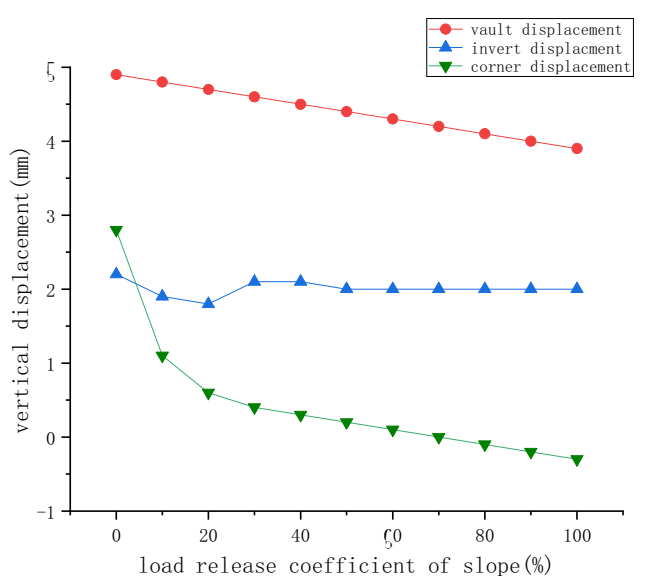

Fig. 5. Vertical Displacement of Anti-Slide Pile and Half-Arch Inclined-Column Structure (mm).

From Figure 4 and Figure 5, we can see that the load release coefficient of slope has a great effect on the horizontal displacement of the vault of the anti-slide pile and half-arch inclined-column structure and on the vertical displacement of the side wall corner, and has a small effect on the overall deformation of the invert. When $\mathrm{K}$ is $0 \%$, the structure endures all the deformation of the side slope, the horizontal displacement of the antislide pile and vault is the largest, and the vertical displacement of the side wall corner is the largest. When $\mathrm{K}$ is $20 \%$, the back pressure is applied on the side slope by backfilling to the extent that structure and the side slope share the deformation to reach equilibrium between them, the horizontal displacement of the antislide pile and vault is the smallest, and the vertical displacement of the side wall corner decreases rapidly. When $\mathrm{K}$ is more than $20 \%$, the deformation of the vault and the side wall corner tends to become equilibrium, and the horizontal displacement of the anti-slide pile gets smaller. To sum up, when the load release coefficient of slope is greater than $20 \%$, the half-tunnel structure system tends to be stable and the deformation of the structure becomes smaller; when it is $100 \%$, the deformation of the structure without side slope is the smallest. 


\subsubsection{Effect of different load release coefficients of slope on internal force of structure without side slope}

Under different load release coefficients of slope, the largest value of maximum principal stress of the structure without side slope in the half-tunnel structure system appears between the backfill layers at the hance, and the largest value of minimum principal stress appears at the foot of wall and column. The stress changing with the load release coefficient of slope from $0 \%$ to $100 \%$ is shown in Figure 6.

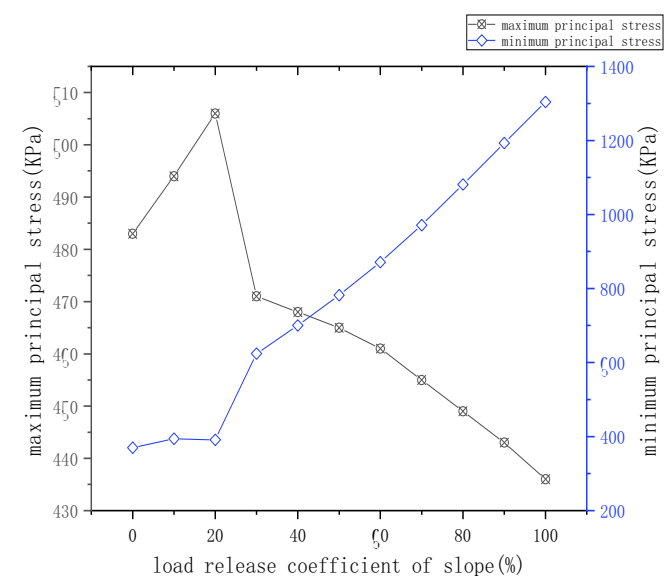

Fig. 6. Principal Stress of Structure without Side Slope (KPa).

From Figure 6, we can see that the load release coefficient of slope has an effect on the stress in the structure without side slope, and that the interaction between the side slope and the structure in the halftunnel structure system provides resistance for each other's deformation. When $\mathrm{K}$ is less than $20 \%$, the stress in the half-tunnel structure system is dominated by the deformation-induced stress in the side slope, and the tensile stress in the structure is large while the compressive stress is small, indicating the whole structure is unstable. When $\mathrm{K}$ is more than $20 \%$, the stress in the half-tunnel structure system tends to be stable, and with the increase of the load release coefficient of slope, the tensile stress in the structure decreases and the compressive stress increases.

\subsubsection{Effect of different load release coefficients of slope on deformation and internal force of side slope}

The displacement and stress changes of the side slope in the half-tunnel structure system are obviously correlated with the load release coefficient of slope, as shown in Figure 7 and Figure 8. The load release coefficient of slope is the percentage of the load released after excavation and before consolidation of a side slope. With the increase of the load release coefficient of slope, the horizontal displacement and tensile stress on the top of slope gets larger and the stability of slope gets worse. When $\mathrm{K}$ reaches $80 \%$, the displacement and tensile stress on the top of slope change sharply. Just from the point of view of stability of side slope after excavation, the construction of structure without side slope should start as early as possible.

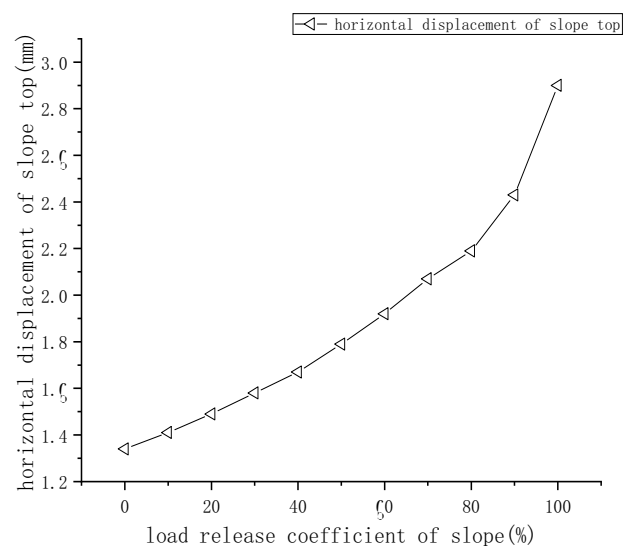

Fig. 7. Horizontal Displacement of Slope Top (mm).

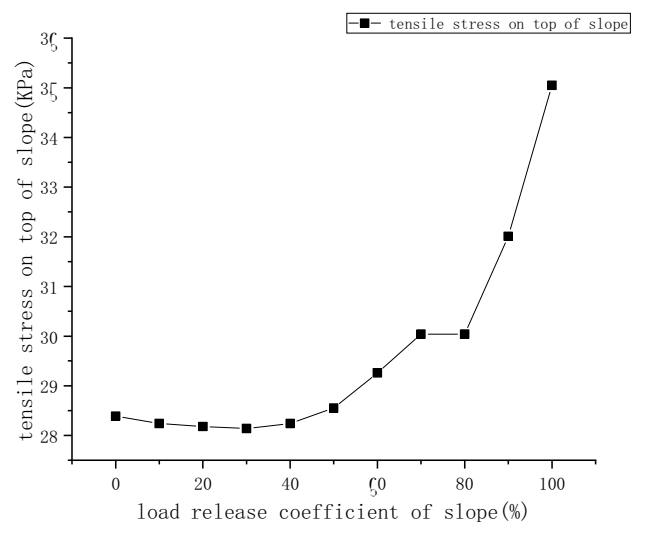

Fig. 8. Tensile Stress on Top of Slope (KPa).

\section{Monitoring and Measurement on Construction Site}

According to the record in the report on monitoring and measurement on construction site[8], the concreting of the invert and pile foundation of the half-tunnel was completed on July 29. From that day on, the finished invert and pile foundation began to bear the deformation pressure of the side slope. Here, this is regarded as the milestone for calculating the load release coefficient of slope. As the deformation of the second and third-stage side slopes has been stable during the construction of the half-tunnel structure, now we focus on the first-stage side slope. From the displacement curve of the first-stage side slope of the half-tunnel, it is known that the displacement change of the first-stage side slope in $\mathrm{X}$ and $\mathrm{Y}$ directions tends to be stable, and the deformation in $\mathrm{Z}$ direction is not yet stable. The displacement in $\mathrm{Z}$ direction of the first-stage side slope of the half-tunnel is shown in Figure 9. The actual load release coefficient of slope of the half-tunnel structure system is derived from the data about the displacement in $\mathrm{Z}$ direction of the first-stage side slope obtained by on-site monitoring and measurement. More specifically, the load release coefficient of slope $(\mathrm{K})$ is the ratio of the displacement with the largest variation $(\mathrm{Ut})$ at the seventh measuring 
point to the final displacement at the same measuring point (U). $\mathrm{K}$ is equal to $60 \%$, suggesting $60 \%$ of the load applied on the side slope has been released when the structure is constructed on site.

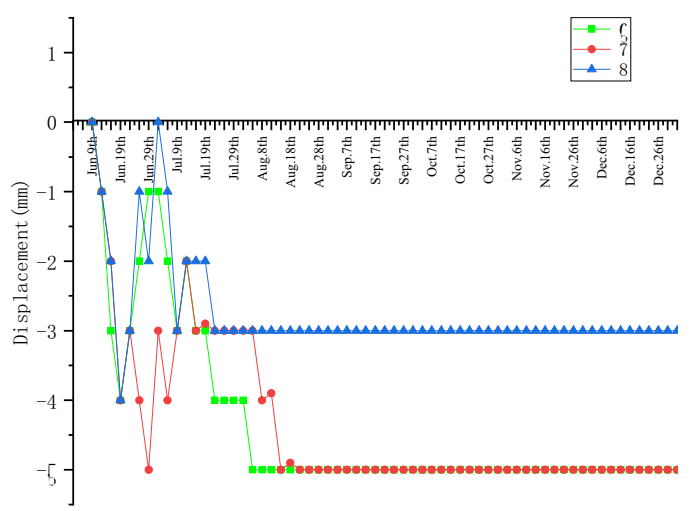

Fig.9. Curve of Displacement iDn Z Direction of First-Stage Side Slope of Half-Tunnel Structure System.

\section{Conclusion}

In this paper, the coupled computation of the side slope, backfilled mass and structure in the half-tunnel structure system is performed by the stratum structure method. The side slope, backfilled mass and structure are modeled as a whole, and the interaction among them is considered. As to the timing for half-tunnel construction, the concept "Load Release Coefficient of Slope" is developed for the first time. After the analysis of the changes in the construction mechanics of the combined system under different spatial-temporal conditions, in the light of the data of monitoring and measurement on construction site, the good timing for construction of half-tunnel structure system has be ascertained. It is concluded as follows:

(1) The half-tunnel is a system combining side slopes, backfilled masses and half-tunnel structure, which interact with each other. The half-tunnel construction should allow for the coordination of the three combination factors.

(2) When $\mathrm{K}<20 \%$, the internal force and deformation of the half-arch inclined-column structure in the half-tunnel structure system are unstable, and the deformation of the side slope is small. When $20 \% \leq \mathrm{K}<$ $80 \%$, the internal force and deformation of the half-arch inclined-column structure in the half-tunnel structure system tend to be stable, and the internal force and deformation of the side slope increases. When $80 \% \leq \mathrm{K}$, the internal force and deformation of the half-arch inclined-column structure in the half-tunnel structure system decreases, and the deformation of the side slope accelerates, as a result of which excessive deformation is produced.

(3) Judging from the spatial-temporal change law of construction mechanics of half-tunnel structure system, it is a good time to start the construction of halftunnel structure when the load release coefficient of slope is about $70 \%$. In addition, the timing for construction of structure can be determined using the construction technology based on the information feedback after on-site monitoring and measurement, so as to achieve the purpose of safety and economy.

\section{References}

1. P. Mo, Technology of Highway and Transport, Commun. 5, 140-146 (2013)

2. F. Q. Han, X. B. Hu, Technology of Highway and Transport, Commun. 32, 94-99 (2016)

3. S. P. Jiang, Large span special shaped shed tunnel structure of mountainous highway (Science Press, Bei Jing, 2010)

4. Q. Huang, J. L. Liu, et al., Technical Code for Building Pile Foundations, (China Architecture \& Building Press, Bei Jing, 2008)

5. S. P. Jiang, L. D. Yang, et al., Code for Design of Road Tunnel, (China Communications Press, Bei Jing, 2004)

6. C. H. Liao, X. H. Guo, et al., Guidelines for Design of Highway Tunnel, (China Communications Press, Bei Jing, 2010)

7. M. C. Wang, M. Shao, Basic Principle and Numerical Method of Finite Element, (Tsinghua University Press, Bei Jing, 1997)

8. Zhi Lian Technology, (2015) Weekly Monitoring and Measurement Report. http://www. hnlzqs. com/. 